\title{
Atomic arrangement, composition and orientation of hexagonal BCN films synthesized by radiofrequency plasma enhanced CVD
}

\author{
Md. Abdul MANNAN, ${ }^{\dagger}$ Tetsuya KIDA, Hideyuki NOGUCHI, Masamitsu NAGANO, \\ Iwao SHIMOYAMA, ${ }^{*}$ Norie HIRAO* and Yuji BABA*
}

Department of Chemistry and Applied Chemistry, Faculty of Science and Engineering, Saga University, 1, Honjo, Saga 840-8502 *Synchrotron Radiation Research Unit, Quantum Beam Science Directorate, Japan Atomic Energy Agency,

Tokai-mura, Ibaraki 319-1195

\begin{abstract}
Oriented hexagonal BCN films were synthesized on Si $\left(\begin{array}{lll}1 & 0 & 0\end{array}\right)$ substrate by radiofrequency plasma enhanced chemical vapor deposition using tris-(dimethylamino)borane as a precursor. The formation of the crystalline hexagonal BCN hybrids was confirmed by FT-IR and XRD. $\mathrm{CH}_{4}+\mathrm{H}_{2}$ carrier gas increased the $\mathrm{C}$ content in the films in comparison with $\mathrm{N}_{2}$ carrier gas. XPS measurement showed that the films were composed of a variety of $\mathrm{B}-\mathrm{N}, \mathrm{B}-\mathrm{C}, \mathrm{C}-\mathrm{N}$ bonds to form the $\mathrm{BCN}$ atomic hybrids. The $\pi^{*}$ resonance peak in the B K-edge NEXAFS spectra also indicated the presence of the $s p^{2}$ hybrid configuration of B-C-N bonds like $\mathrm{BN}_{3}$ in $\mathrm{h}-\mathrm{BN}$. The $\sigma^{*}$ resonance peaks suggested the diversity in the $\sigma$ bonds in the films. Orientation of the h-BCN hybrids was suggested on the basis of the polarization dependence of NEXAFS.
\end{abstract}

(2009 The Ceramic Society of Japan. All rights reserved.

Key-words : h-BCN, PECVD, XPS, NEXAFS

[Received November 5, 2008; Accepted January 15, 2009]

\section{Introduction}

Considerable efforts have been given to the synthesis of boron carbonitride $(\mathrm{BCN})$ compounds in the last few years. The cubic phase $(\mathrm{c}-\mathrm{BCN})$ is expected to be a superhard compound comparable to diamond. ${ }^{1)}$ The hexagonal phase (h-BCN) is attractive in the application to electronic and luminescent devices due to its semi-conducting property with variable band-gap energy. ${ }^{2)}$ It might also be applicable to the rechargeable Li-ion battery. ${ }^{3)}$ Syntheses of the ternary BCN compounds with the various compositions using different methods have been reported, though most of the reported $\mathrm{BCN}$ compounds are the mixtures of the nano-crystalline hexagonal and cubic phases or the amorphous phase. ${ }^{4)-6)}$ Single phase of the h-BCN with large grain size has not been synthesized up to now and efforts were not devoted to clarify the atomic arrangement precisely in the $\mathrm{BCN}$ films. Therefore, preparation of the single $\mathrm{h}-\mathrm{BCN}$ phase is still a challenge.

Previously, we prepared h-BCN hybrid films on Si $\left(\begin{array}{lll}1 & 0 & 0\end{array}\right)$ by radiofrequency plasma enhanced chemical vapor deposition (RF-PECVD) using tris-(dimethylamino)borane (TDMAB) as the single-source molecular precursor with $\mathrm{H}_{2}$ carrier gas. ${ }^{7}$ However, the crystalline phase was not detected by XRD, probably due to the short-range order of the atomic arrangement or the amorphous phase. The $\mathrm{C}$ content in the films was also low $(<18$ at.\%) compared with $\mathrm{B}$ and $\mathrm{N}$.

In this work, crystalline $\mathrm{h}-\mathrm{BCN}$ hybrid films with higher $\mathrm{C}$ content (22 to 35 at.\%) have been prepared by using $\mathrm{N}_{2}$ or $\mathrm{CH}_{4}+\mathrm{H}_{2}$ mixture as the carrier gas. In this paper, we report the atomic arrangement, composition and orientation of the crystalline h-

\footnotetext{
Corresponding author: A. Mannan; E-mail: amannan75@yahoo.
} com
BCN films prepared by RF-PECVD.

\section{Experimental}

$\mathrm{BCN}$ films were synthesized on $\mathrm{Si}\left(\begin{array}{lll}1 & 0 & 0\end{array}\right)$ substrate by RF-PECVD using TDMAB as the single-source molecular precursor. The detail of the deposition system has been described elsewhere. ${ }^{7)} \mathrm{N}_{2}$ or $\mathrm{CH}_{4}+\mathrm{H}_{2}$ mixture was used as the carrier gas. The RF power was varied from 400 to $800 \mathrm{~W}$. Four samples synthesized under the different reaction conditions were considered in this study. Samples (1) and (2) were synthesized at the RF power of 800 and $500 \mathrm{~W}$, respectively by flowing $\mathrm{N}_{2}$ carrier gas. Samples (3) and (4) were synthesized at the RF power of 700 and $400 \mathrm{~W}$, respectively by flowing $\mathrm{CH}_{4}(10 \%)+\mathrm{H}_{2}(90 \%)$ mixture.

The chemical bond and the crystalline phase were explored by Fourier transform infrared spectroscopy (FT-IR) and X-ray diffraction (XRD). The chemical composition and the atomic arrangement were studied by X-ray photoelectron spectroscopy (XPS) and Near-edge X-ray absorption fine structure (NEXAFS) measurements. The XPS and NEXAFS measurements were performed at the Beam Line 11A and Beam Line 27A of Photon Factory, KEK, using the linearly polarized synchrotron radiation. The elemental composition (atomic ratio of $\mathrm{B}, \mathrm{C}$ and $\mathrm{N}$ ) was determined from the intensity of the $\mathrm{B} 1 \mathrm{~s}, \mathrm{C} 1 \mathrm{~s}$ and $\mathrm{N} 1 \mathrm{~s}$ peaks in the XPS wide scan spectra. ${ }^{7)}$ The $\mathrm{B} 1 \mathrm{~s}, \mathrm{C} 1 \mathrm{~s}$ and N1s binding energies were calibrated by $\mathrm{Au} 4 f_{7 / 2}$ binding energy $(84.0 \mathrm{eV})$. In the NEXAFS analyses, the X-ray incidence angle $\theta$ is defined as the angle between the electric field vector of the linearly polarized $\mathrm{X}$-ray and the surface normal of the film. ${ }^{8)}$

\section{Results}

\subsection{FT-IR analyses}

Figure 1 shows FT-IR transmission spectra of the samples synthesized at different RF powers in the $\mathrm{N}_{2}$ and $\mathrm{CH}_{4}+\mathrm{H}_{2}$ car- 


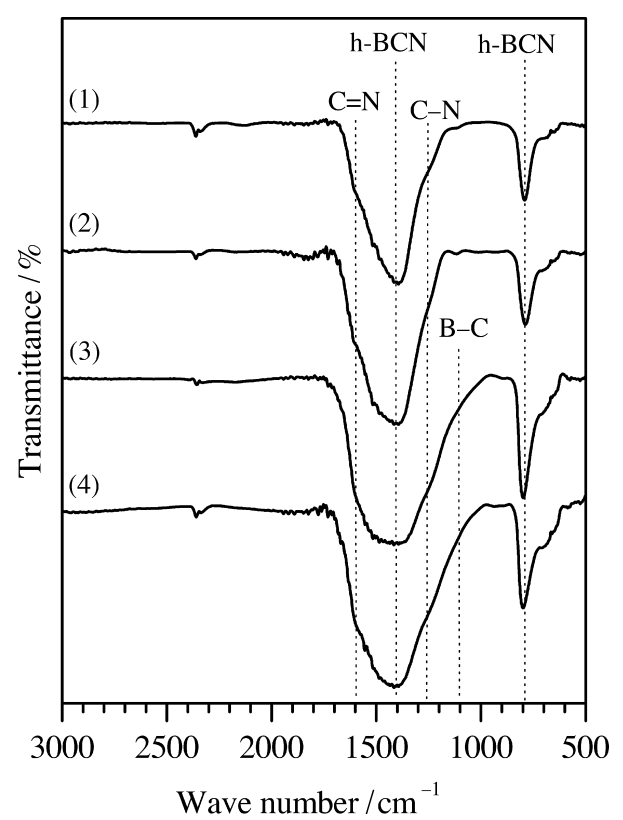

Fig. 1. FT-IR transmission spectra of the as-deposited samples. The numbers (1)-(4) on the left side of the spectra represent the respective sample: Samples (1) and (2) were synthesized at 800 and $500 \mathrm{~W}$, respectively in $\mathrm{N}_{2}$ carrier gas. Samples (3) and (4) were synthesized at 700 and $400 \mathrm{~W}$, respectively in $\mathrm{CH}_{4}+\mathrm{H}_{2}$ carrier gas.

rier gases. The spectra showed two peaks; a broad peak around at $1400 \mathrm{~cm}^{-1}$ and a relatively sharp peak at $800 \mathrm{~cm}^{-1}$. These peak positions are almost compatible with the $\mathrm{sp}^{2}$-bonded $\mathrm{B}-\mathrm{N}$ bonds in h-BN. ${ }^{4), 9)}$ These samples contain 22 (sample 1), 23 (sample 2), 35 (sample 3) and 35 (sample 4) at.\% of C respectively, together with $\mathrm{B}$ and $\mathrm{N}$ as confirmed by the XPS measurements. Therefore, these peaks suggest the formation of the hexagonal $\mathrm{sp}^{2}$ $\mathrm{B}-\mathrm{C}-\mathrm{N}$ atomic hybrid bonds in these films similar to the $\mathrm{sp}^{2}$ B-N bonds in h-BN. The broader peaks for samples (3) and (4) \{Full Width at Half Maximum (FWHM $\left.\left.=\sim 390 \mathrm{~cm}^{-1}\right)\right\}$ than those for samples (1) and (2) (FWHM $=\sim 275 \mathrm{~cm}^{-1}$ ) may be due to the more $\mathrm{C}$ incorporation in the films. The observed broadening of the peak from 1000 to $1700 \mathrm{~cm}^{-1}$ could be explained as a consequence of the formation of the $\mathrm{C}=\mathrm{N}, \mathrm{C}-\mathrm{N}, \mathrm{B}-\mathrm{C}$ bonds as well as the $\mathrm{B}-\mathrm{N}$ bond in the films, since these bonds are reported in this region. ${ }^{10)}$ The increase of $\mathrm{C}$ content might result in the increase of the complex combination of $\mathrm{B}-\mathrm{N}, \mathrm{C}-\mathrm{N}$ and $\mathrm{B}-\mathrm{N}$ bonds in the h-BCN hybrids. Formation of a separate phase of binary compound such as $\mathrm{BN} / \mathrm{CN}_{x} / \mathrm{BC}_{x}$ was not assumed as the peak splitting was not found in these spectra.

\subsection{XRD analyses}

XRD patterns of the 4 samples are shown in Fig. 2. Two diffraction peaks observed at $26.3^{\circ}$ and at $29.2^{\circ}$ for these samples seemingly suggest the existence of a crystalline structure in these films. The ( $\left(\begin{array}{lll}0 & 0\end{array}\right)$ diffraction peaks of the h-BN and graphite are reported at $2 \theta=26.8^{\circ}(d=3.42 \AA)$ and at $2 \theta=26.6^{\circ}(d=3.36 \AA)$, respectively. ${ }^{11)}$ Therefore, the peak at $26.3^{\circ}(d=3.47 \AA)$ could be ascribed to the hexagonal BCN phase as confirmed by FT-IR. The large interplanar distance compared with h-BN and graphite suggests that the h-BCN basal planes are packed a little bit rougher than $\mathrm{h}-\mathrm{BN}$ and graphite, because of the ternary atomic mixing in the $\mathrm{sp}^{2}$ basal plane. The peak was stronger for the samples (3) and (4) prepared in $\mathrm{CH}_{4}+\mathrm{H}_{2}$ than those for sample (1) and (2) prepared in $\mathrm{N}_{2}$ carrier gas. The more $\mathrm{C}$ content might

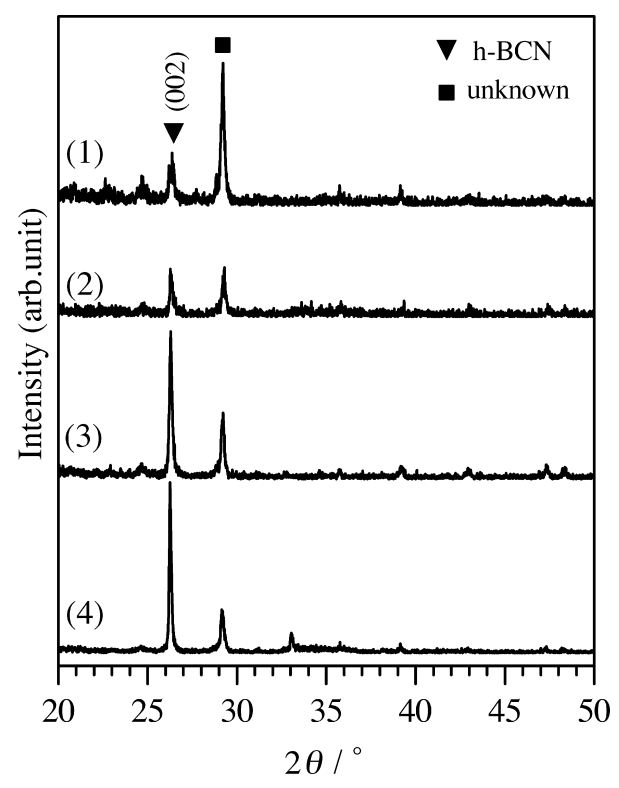

Fig. 2. XRD patterns of the samples shown in Fig. 1. Samples (1) and (2) were synthesized at 800 and $500 \mathrm{~W}$, respectively in $\mathrm{N}_{2}$ carrier gas. Samples (3) and (4) were synthesized at 700 and $400 \mathrm{~W}$, respectively in $\mathrm{CH}_{4}+\mathrm{H}_{2}$ carrier gas.

enhance the formation of the hexagonal phase in these films.

The peak at $2 \theta=29.2^{\circ}(d=3.16 \AA)$ has not been reported yet for the BCN compounds. This unknown peak was strong for samples (1) and (3) prepared at the higher RF power than the samples (2) and (4) at the lower RF power. Auxiliary experiments using different substrates such as $\mathrm{Ni}$, $\mathrm{Ti}$ and $\mathrm{Au}$ were performed in order to confirm this unknown peak. The peak at $29.2^{\circ}$ was also revealed on all the substrates. Therefore, the unknown peak must be ascribed to a crystalline $\mathrm{BCN}$ phase though more studies are needed to identify the origin of this peak.

\subsection{XPS analyses}

The B1s, C1s and N1s XPS spectra of the samples are shown in Fig. 3, together with their compositions estimated from the XPS wide scan spectra: $\mathrm{B}_{44} \mathrm{C}_{22} \mathrm{~N}_{34}$ (sample 1), $\mathrm{B}_{45} \mathrm{C}_{23} \mathrm{~N}_{32}$ (sample 2), $B_{36} C_{35} \mathrm{~N}_{29}$ (sample 3) and $\mathrm{B}_{38} \mathrm{C}_{35} \mathrm{~N}_{27}$ (sample 4), respectively. When the $\mathrm{N}_{2}$ carrier gas was used, the $\mathrm{C}$ content in the films was low compared with $\mathrm{B}$ and $\mathrm{N}$ (samples 1 and 2). $\mathrm{CH}_{4}+\mathrm{H}_{2}$ carrier gas increased the $\mathrm{C}$ content (samples 3 and 4). This may be due to the higher reactivity of the fragments of $\mathrm{CH}_{4}$ than that of the $\mathrm{N}_{2}$ fragments in the plasma.

The B1s, C1s and N1s spectra of the samples prepared in the $\mathrm{N}_{2}$ and the $\mathrm{CH}_{4}+\mathrm{H}_{2}$ carrier gases did not change with the RF power. We, therefore, discussed in detail on the samples (1) and (3) prepared in $\mathrm{N}_{2}$ and $\mathrm{CH}_{4}+\mathrm{H}_{2}$ carrier gas, respectively. The B1s peak could be fitted almost by a single Gaussian curve as shown in a broken line (Fig. 3(a)). However, the full-width at half maximum $(\mathrm{FWHM}=\sim 3.0 \mathrm{eV}$ ) of the $\mathrm{B} 1 \mathrm{~s}$ peaks was wide in comparison with that of the $\mathrm{h}-\mathrm{BN}(\sim 1.7 \mathrm{eV}) .{ }^{12)}$ It suggests that $\mathrm{B}$ atoms have various chemical environments. Therefore, the XPS spectra were deconvoluted into component peaks in order to discuss the possible chemical environments in more detail.

The B1s spectra could be well fitted by deconvoluting into two Gaussian peaks centered at 190.8 and $189.6 \mathrm{eV}$, respectively. These component peaks were assigned to the $\mathrm{B}-\mathrm{N}$ and the $\mathrm{sp}^{2}$ $\mathrm{B}-\mathrm{C}-\mathrm{N}$ atomic hybrid bonds based on their reported binding 
(a)

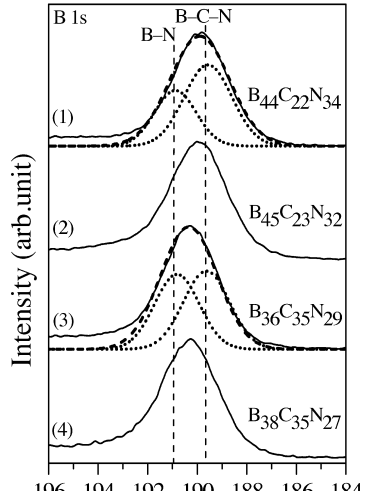

(b)

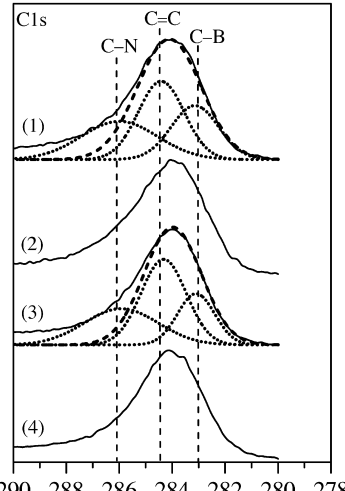

(c)

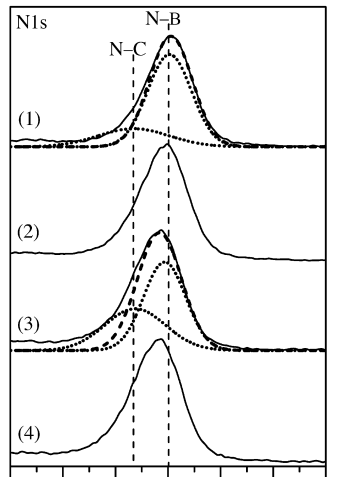

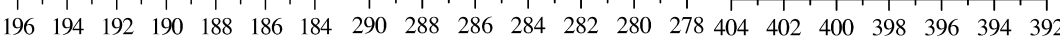

Binding energy/eV

Fig. 3. XPS spectra of the samples shown in Fig. 1; (a) B1s, (b) C1s and (c) N1s together with the single Gaussian peak (broken line) and the deconvoluted component peaks (dotted line). The compositions of the samples are also shown.

energies. ${ }^{13)}$ However, it is not easy to distinguish between them because the $\mathrm{B}, \mathrm{C}$ and $\mathrm{N}$ atoms are bonded in the chemical environment similar to the $\mathrm{sp}^{2}$-B-N-like configurations in h-BN, and the $\mathrm{h}-\mathrm{BN}$ and the graphite are isoelectronic. As the $\mathrm{C}$ content increased and the B content decreased (sample 3), the B1s peak slightly shifted to the higher energy. This may be due to a distortion of the $\mathrm{sp}^{2}-\mathrm{B}-\mathrm{C}-\mathrm{N}$ chemical environment with the incorporated $\mathrm{C}$.

The $\mathrm{C} 1 \mathrm{~s}$ spectra were also fitted with a single Gaussian curve (Fig. 3(b)). However, the peaks were broad $(\mathrm{FWHM}=\sim 3.5 \mathrm{eV})$ and tailing of the spectra to the higher energy was clearly observed. Therefore, the spectra were also fitted by deconvoluting into three component peaks. The peak centered at $283.1 \mathrm{eV}$ suggests the formation of the $\mathrm{C}-\mathrm{B}$ bond because the $\mathrm{C} 1 \mathrm{~s}$ binding energies for $\mathrm{BC}_{3.4}$ and $\mathrm{B}_{4} \mathrm{C}$ have been reported to be 284.3 and $283.0 \mathrm{eV}$, respectively. ${ }^{14)}$ The peak centered at $284.4 \mathrm{eV}$ could be ascribed to the graphite-like $\mathrm{C}=\mathrm{C}$ bonds. ${ }^{15)}$ However, no evidence for the separate graphite phase was found. The component peak centered at $286.0 \mathrm{eV}$ is due to $\mathrm{C}$ atom bonded to more electronegative $\mathrm{N}$ atom. ${ }^{16)}$ Therefore, the $\mathrm{C}$ atoms may also be bonded to $\mathrm{B}$ and $\mathrm{N}$ to form the $\mathrm{B}-\mathrm{C}-\mathrm{N}$ hybrid bonds while formation of the $\mathrm{CN}_{x}$ phase can not be excluded.

The N1s spectra of the samples could be fitted with a broad single Gaussian curves (Fig. 3(c)) as well as the B1s spectra. The broadening suggests the formation of the $\mathrm{BCN}$ atomic hybrids with a variety of configurations. These spectra could also be fitted by deconvoluting two component peaks at least. The deconvoluted peak centered at $398.0 \mathrm{eV}$ could be assigned to the $\mathrm{N}-\mathrm{B}$ bond. ${ }^{15)}$ The N-B bond is predominant in accordance with the $\mathrm{B}-\mathrm{N}$ bond found in the B1s spectra. The component peak centered at the higher binding energy $(399.3 \mathrm{eV})$ is due to the formation of $\mathrm{N}-\mathrm{C}$ bond. The $\mathrm{N}-\mathrm{C}$ bond was also suggested from the $\mathrm{C} 1 \mathrm{~s}$ spectra although the $\mathrm{N}-\mathrm{C}$ bond in sample (1) was not obvious because of no clear distinction between the h-BN-like configuration and the h-BCN configuration.

It is confirmed from these XPS results that the films are composed of different B-N, B-C, C-N bonds to form the $\mathrm{sp}^{2}-\mathrm{BCN}$ atomic hybrid configurations. No clear evidence of the phase separation such as $\mathrm{BN} / g r a p h i t e / \mathrm{CN}_{x} / \mathrm{BC}_{x}$ was observed while the tailing of the $\mathrm{C} 1 \mathrm{~s}$ peaks to the higher binding energy suggested the formation of the small amount of the $\mathrm{CN}_{x}$ phase together with the h-BCN hybrids.
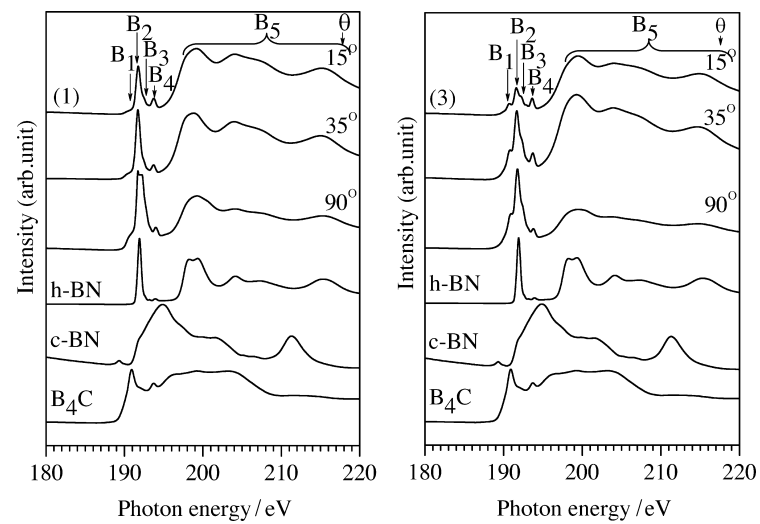

Fig. 4. B K-edge NEXAFS spectra at various incidence angle $(\theta)$ of the X-ray for samples (1) and (3). NEXAFS spectrum for h-BN, c-BN and $\mathrm{B}_{4} \mathrm{C}$ powders are also shown for comparison.

\subsection{Polarization dependence of NEXAFS spectra}

The polarization dependence of B K-edge NEXAFS spectra of the typical samples (1) and (3) are shown in Fig. 4, together with the spectra of the h-BN, c-BN and $\mathrm{B}_{4} \mathrm{C}$ powders as the references. $A$ broad peak (peak $\mathrm{B}_{2}$ ) has been predominantly observed at the photon energy of $191.8 \mathrm{eV}$ at the normal incidence $\left(\theta=90^{\circ}\right)$ of the X-ray.

The predominant peak could be ascribed to the $\pi^{*}$ resonance of $\mathrm{sp}^{2}-\mathrm{B}-\mathrm{C}-\mathrm{N}$ bonds, suggesting the formation of the $\mathrm{sp}^{2}-\mathrm{BCN}$ hybrids with a similar configuration to $\mathrm{BN}_{3}$ in h-BN. At the grazing incidence angle $\left(\theta=15^{\circ}\right)$, the $\mathrm{B}_{2}$ peak decreased and some fine structures such as $\mathrm{B}_{1}, \mathrm{~B}_{3}$ and $\mathrm{B}_{4}$ appeared evidently. It indicates the formation of various atomic configurations around $\mathrm{B}$ atoms besides the $\mathrm{BN}_{3}$-like configuration. The peak $\mathrm{B}_{1}$ could be ascribed to the $\mathrm{B}$ atoms bonded to $\mathrm{B}$ in $\mathrm{B}_{4} \mathrm{C}$-like configuration because of the similar photon energy to $\mathrm{B}_{4} \mathrm{C} .{ }^{17)}$ The peak $\mathrm{B}_{3}$ could be due to different configuration from the $\mathrm{BN}_{3}$ like configuration. However, it could not be simply ascribed to the $\mathrm{B}$ atoms bonded to $\mathrm{N}$ and $\mathrm{C}$ atoms such as $\mathrm{BN}_{2} \mathrm{C}$ or $\mathrm{BNC}_{2}$ configuration since the photon energy of $\mathrm{B}$ K-edge might decrease by substituting $\mathrm{C}$ for more electronegative $\mathrm{N}$ atoms around the $\mathrm{B}$ atoms. The steric configurations of these different atomic hybrids of BCN have not been identified clearly yet although different 

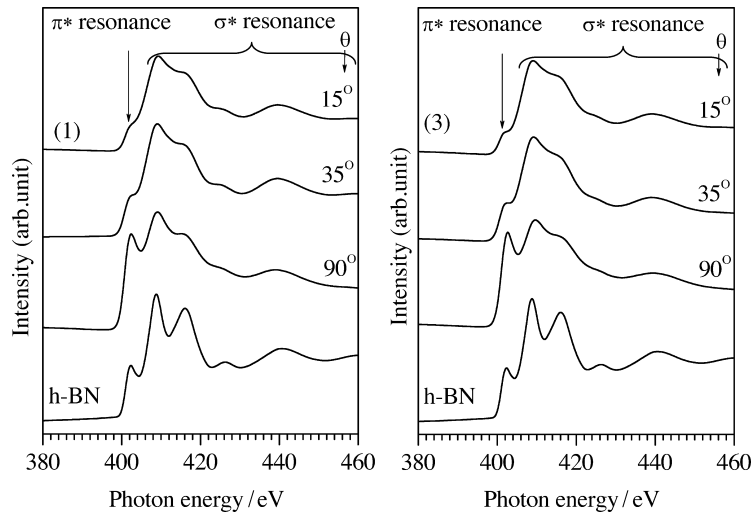

Fig. 5. N K-edge NEXAFS spectra at various incidence angle $(\theta)$ of the X-ray for the samples (1) and (3). NEXAFS spectrum for h-BN powder is also shown for comparison.

$\mathrm{BCN}$ atomic hybrid configurations with different $\mathrm{N}$ vacancies might be formed. ${ }^{18)}$ The peak $\mathrm{B}_{4}$ is reported to be the $\mathrm{B}-\mathrm{O}$ bond which is estimated as the surface contamination. ${ }^{19)}$ We could not estimate the cubic phase of $\mathrm{BCN}$ comparing with the reference spectrum of c-BN. The notable decrease in the $\mathrm{B}_{2}$ peak height and increase in the $\sigma^{*}$ resonance peak (broad feature denoted by $\mathrm{B}_{5}$ ) were found as the incidence angle decreased. It suggests that the h-BCN layers with the $\mathrm{BN}_{3}$-like configuration may orient in the direction perpendicular to the silicon substrate. ${ }^{20)}$ The $\mathrm{B}_{5}$ peaks for the both samples are gentle compared with those for the h-BN, indicating that the atomic arrangement around the $\mathrm{B}$ atoms are not so well ordered as in h-BN. The decrease of the $B_{2}$ peak height for sample (1) was not pronounced and the $B_{1}$ and $\mathrm{B}_{3}$ fine structures were not obvious in comparison with those for sample (3). This implies the predominant existence of the h-BCN configuration like h-BN in sample (1). The predominance of the $\mathrm{B}_{2}$ configuration for sample (1) also corresponds to the sharp FT-IR peak and the unknown XRD peak at $29.2^{\circ}$.

The polarization dependence of $\mathrm{N}$ K-edge NEXAFS spectra of the typical samples (1) and (3) are shown in Fig. 5, together with the spectrum of the h-BN powder as the reference. Similar to the B K-edge spectra, the $\pi^{*}$ resonance peak of N K-edge decreased at the grazing incidence of the X-ray. It confirms the orientation of the h-BCN basal planes perpendicular to the silicon substrate surface. However, fine structures are not appearing in the N Kedge spectra and the spectra for sample (1) and sample (3) are very similar to each other. This observation suggests that the atomic arrangement around $\mathrm{N}$ atoms in these samples is homogenous and very similar to each other in comparison with those around the $\mathrm{B}$ atoms.

The $\sigma^{*}$ resonance peaks are more gentle than those of the h$\mathrm{BN}$, suggesting the diversity in the $\sigma$ bonds around $\mathrm{N}$ atoms than h-BN. While $\mathrm{N}$ atoms in h-BN crystal are regularly surrounded by $3 \mathrm{~B}$ atoms, the regularity might be reduced in the long range in these samples, probably because of the atomic mixing of $\mathrm{B}$, $\mathrm{C}$ and $\mathrm{N}$ in the basal planes. However, it is difficult to distinguish the atomic arrangements around $\mathrm{N}$ atom because the peak energies corresponding to the $\mathrm{N}-\mathrm{B}$ and $\mathrm{N}-\mathrm{C}$ bonds lie very close to each other. ${ }^{21)}$

\section{Discussion}

Based on the results by FT-IR, XRD, XPS and NEXAFS analyses, we discuss on the atomic arrangement, composition and orientation of the h-BCN films prepared by RF-plasma CVD in different carrier gases.

\subsection{Atomic arrangement}

All samples prepared in this work exhibited two absorption bands at $\sim 1400$ and $\sim 800 \mathrm{~cm}^{-1}$ in their FT-IR spectra (Fig. 1), which are similar to those ascribed to the $\mathrm{sp}^{2}-\mathrm{B}-\mathrm{N}$ bonds in $\mathrm{h}-$ $\mathrm{BN}$. The samples contained $22-35$ at.\% $\mathrm{C}$ determined by XPS. Therefore, we propose the formation of the ternary mixing of the $\mathrm{sp}^{2}-\mathrm{B}-\mathrm{C}-\mathrm{N}$ atomic hybrid bonds. The broadening of the FT-IR peaks might be due to the coexistence of a variety of bonds such as $\mathrm{B}-\mathrm{N}, \mathrm{B}-\mathrm{C}$ and $\mathrm{C}-\mathrm{N}$ and their combinations because these bonds exhibit the IR absorption peaks in this reason. ${ }^{10)}$ The broadening of the spectra with the $\mathrm{C}$ concentration suggests the increase in the complexity of the combination of $\mathrm{C}-\mathrm{N}, \mathrm{C}-\mathrm{B}$ and $\mathrm{B}-\mathrm{N}$ bonds. No clear evidence was found for the formation of mixture of the binary compounds such as $\mathrm{BN} / \mathrm{CN}_{x} / \mathrm{BC}_{x}$.

The hexagonal structure was also detected for the present samples in terms of the $\left(\begin{array}{lll}0 & 0 & 2\end{array}\right)$ peak in the XRD patterns (Fig. 2), confirming the formation of the long range order in the atomic arrangement which was not found in the previous work. ${ }^{7)}$ The unknown XRD peak at $29.2^{\circ}$ which suggested another crystalline phase was remarkable for sample (1), however more studies are needed to clarify the unknown phase. Based on the FT-IR and $\mathrm{XRD}$ results we unambiguously propose the hexagonal (h-BCN) atomic arrangement in the present samples.

The XPS spectra (Fig. 3) suggest that the films are composed of different $\mathrm{B}-\mathrm{N}, \mathrm{B}-\mathrm{C}$ and $\mathrm{C}-\mathrm{N}$ bonds to form the $\mathrm{sp}^{2}-\mathrm{BCN}$ atomic hybrid configurations. The wider FWHM of the B1s peaks in comparison with that of h-BN suggests that $\mathrm{B}$ atoms have various chemical environments other than the $\mathrm{BN}_{3}$ configuration similar to h-BN. The little shift of the B1s XPS spectra to the higher binding energy for samples (3) and (4) with higher $\mathrm{C}$ content indicates the distortion of the $\mathrm{sp}^{2}-\mathrm{BCN}$ chemical environment with the $\mathrm{C}$ concentration. The broader $\mathrm{C} 1 \mathrm{~s}$ XPS spectra than the graphite implies that the $\mathrm{C}$ atoms are not only bonded to $\mathrm{C}$ to form the graphite-like configuration but also bonded to $\mathrm{B}$ and $\mathrm{N}$ to form the $\mathrm{sp}^{2}-\mathrm{B}-\mathrm{C}-\mathrm{N}$ atomic environments. Tailing of the spectra to the higher binding energy might be ascribed to the binary phase $\mathrm{CN}_{x}$ together with the $\mathrm{sp}^{2}$-BCN hybrids. The broad N1s XPS spectra and tailing also suggest the formation of the $\mathrm{sp}^{2}-\mathrm{BCN}$ atomic hybrids with a variety of configurations. However, it is difficult to clearly sort out the different configurations of BCN hybrids by the XPS spectra.

All samples showed broad NEXAFS spectra in comparison with h-BN (Fig. 4). The predominant peak $\mathrm{B}_{2}$ suggests the formation of the $\mathrm{sp}^{2}-\mathrm{B}-\mathrm{C}-\mathrm{N}$ configuration like $\mathrm{BN}_{3}$ in h-BN. The shrinking of the predominant peak $\mathrm{B}_{2}$ was pronounced and some fine structures became clearer at the grazing incidence of the $\mathrm{X}$ ray for sample (3) with high $\mathrm{C}$ content. The incorporated $\mathrm{C}$ might reduce the homogeneity in the $\mathrm{h}-\mathrm{BCN}$ network as suggested from the XPS analyses and hence enhance the formation of the $\mathrm{B}_{4} \mathrm{C}$-like configuration (fine structure $\mathrm{B}_{1}$ ) and the different $\mathrm{BCN}$ hybrids (fine structure $\mathrm{B}_{3}$ ) other than the $\mathrm{h}$ - $\mathrm{BN}$-like configuration (fine structure $\mathrm{B}_{2}$ ). The $\pi^{*}$ resonance of $\mathrm{N}$ K-edge decreased without showing fine structures at the grazing incident. This result suggests the atomic arrangements around $\mathrm{N}$ atoms are homogeneous in contrast to those around B atoms.

\subsection{Composition}

The C concentrations in the films (1) and (2) prepared in $\mathrm{N}_{2}$ carrier gas were lower (22 and 23 at.\%, respectively) than those in the films (3) and (4) in $\mathrm{CH}_{4}+\mathrm{H}_{2}$ carrier gas (35 at.\% for both). This may be due to the higher reactivity of the $\mathrm{CH}_{4}$ fragments 
than the $\mathrm{N}_{2}$ in the plasma. In the XRD patterns, the intensity ratio of the hexagonal $\left(\begin{array}{lll}0 & 0 & 2\end{array}\right)$ peak at $26.3^{\circ}$ to the unknown peak at $29.2^{\circ}$ was higher for samples (1) and (2) with lower $\mathrm{C}$ content than the samples (3) and (4) with higher $\mathrm{C}$ content. The broader NEXAFS spectra and more significant fine structures were found for sample (3) than for sample (1). These results suggest that the composition might influence not only the atomic arrangement but also the crystallinity and/or the crystal structure.

\subsection{Orientation}

In the NEXAFS spectra (Fig. 4), considerable decrease of the $\pi^{*}$ resonance of the $\mathrm{sp}^{2}$-BCN hybrid structure with h-BN-like configuration $\left(\mathrm{B}_{2}\right.$ peak) was observed at the grazing incident angle of X-ray in comparison with that at the normal incidence. It is because the direction of the orbital vector $\mathbf{p}$ of $\pi^{*}$ orbital of the $\mathrm{sp}^{2}$-BCN sheets becomes opposite to the electric field vector $\mathbf{E}$ of the incident beam of X-ray at the grazing incidence. ${ }^{8)}$ It hence means that the orientation of the $\mathrm{sp}^{2}-\mathrm{BCN}$ basal planes with h-BN-like configuration was perpendicular to the Si substrate. The polarization dependence of the fine structures other than $\mathrm{B}_{2}\left(\mathrm{~B}_{1}, \mathrm{~B}_{3}\right.$ and $\left.\mathrm{B}_{4}\right)$ were not clear while they clearly appeared at the grazing angle for sample (3). The orientations of the fine structures are so far ambiguous. Similar to the B K-edge, polarization dependence of the $\pi^{*}$ resonance peak for $\mathrm{N}$ K-edge (Fig. 5) also suggests the orientation of the $\mathrm{sp}^{2}$-BCN sheets perpendicular to the Si substrate.

\section{Conclusions}

The BCN films were synthesized by RF-PECVD using TDMAB as the precursor. The formation of the crystalline hexagonal BCN phase with h-BN-like configuration was indicated by FT-IR and confirmed by XRD. XPS measurement showed that the films were composed of a variety of B-N, B-C, C-N bonds to form the $\mathrm{BCN}$ atomic hybrids. No clear evidence for the phase separation such as $\mathrm{BN} / \mathrm{graphite} / \mathrm{CN}_{x} / \mathrm{BC}_{x}$ was found though tailing of the C1s XPS peak to the higher binding energy suggested a $\mathrm{CN}_{x}$ phase together with the $\mathrm{BCN}$ hybrids. $\mathrm{CH}_{4}+\mathrm{H}_{2}$ carrier gas enhanced the $\mathrm{C}$ incorporation into the h-BCN. It was also seen from the NEXAFS measurement that the $\mathrm{BCN}$ atomic hybrids with $\mathrm{sp}^{2}-\mathrm{B}-\mathrm{C}-\mathrm{N}$ bonds consisted mainly of the $\mathrm{BN}_{3}$-like configuration while small amount of the other local configurations were detected. The polarization dependence of NEXAFS indicated that the h-BCN layers may orient in the direction perpendicular to the Si substrate.

Acknowledgements The authors would like to thanks Dr. Y. Kitajima of the Photon Factory for his supports. This work was per- formed under the approval of the Photon Factory Program Advisory Committee (Proposal No. 2006G312).

\section{References}

1) Y. Tateyama, T. Ogitsu, K. Kusakabe, S. Tsuneyuki and S. Itoh, Phys. Rev. B, 55, 10161-10164 (1997).

2) W. R. L. Lambrecht and B. Segall, Phys. Rev. B, 47, 9289-9296 (1993).

3) M. Kawaguchi, Adv. Mater., 9[8], 615-625 (1997).

4) W. J. Pan, J. Sun, H. Ling, N. Xu, Z. F. Ying and J. D. Wu, Appl. Surf. Sci., 218, 297-304 (2003).

5) T. Yuki, S. Umeda and T. Sugino, Diamond Relat. Mater., 13, 1130-1134 (2004).

6) M. Mieno and T. Satoh, J. Mat. Sci., 36, 3925-3931 (2001).

7) M. A. Mannan, M. Nagano, T. Kida, N. Hirao and Y. Baba, $J$. Phys. Chem. Solids, 70, 20-25 (2009). doi:10.1016/j.jpcs. 2008.08.013.

8) J. Stöhr, NEXAFS Spectroscopy, Springer Series in Surface Science, Vol. 25, Springer, New York (1992).

9) Y. Wada, Y. K. Yap, M. Yoshimura, Y. Mori and T. Sasaki, Diamond Relat. Mater., 9, 620-624 (2000).

10) F. Rossi, B. Andre, A. Van Veen, P. E. Mijnarends, H. Schut, F. Labohm, M. P. Delplancke and K. Hubbard, J. Mater. Res., 9, 2440-2449 (1994).

11) R. Torres, I. Caretti, R. Gago, Z. Martín and I. Jiménez, Diamond Relat. Mater., 16, 1450-1454 (2007).

12) M. N. Uddin, I. Shimoyama, Y. Baba, T. Sekiguchi and M. Nagano, J. Vac. Sci. Technol. A, 23[3], 497-502 (2005).

13) M. A. Mannan, M. Nagago, N. Hirao and Y. Baba, Chem. Lett., 37, 96-97 (2008).

14) M. O. Watanabe, T. Sasaki, S. Itoh and K. Mizushima, Thin Solid Films, 281-282, 334-336 (1996).

15) A. Perrone, A. P. Caricato, M. Dinescu, V. Sandu and A. Andrei, Appl. Surf. Sci., 133, 239-242 (1998).

16) V. Linss, S. E. Rodil, P. Reinke, Garnier, U. Kreissig and F. Richter, Thin Solid Films, 467, 76-87 (2004).

17) R. Gago, I. Jiménez, I. García and J. M. Albella, Vacuum, 64, 199-204 (2002).

18) I. Jiménez, A. F. Jankowski, L. J. Terminello, J. A. Carlisle, D. G. J. Sutherland, G. L. Doll, W. M. Tong and D. K. Shuh, Phys. Rev. B, 55, 12025-12037 (1997).

19) R. Franke, St. Bender, H. Jüngermann, and M. Jansen, Elec. Spec. Relat. Phenom., 101-103, 641-645 (1999).

20) R. Gago, I. Jiménez, T. Sajavaara and J. M. Albella, Diamond Relat. Mater., 10, 1165-1169 (2001).

21) S. C. Ray, H. M. Tsai, J. W. Chiou, J. C. Jan, K. Kumar, W. F. Pong, F. Z. Chien, M. H. Tsai, S. Chattopadhyay, L. C. Chen, S. C. Chien, M. T. Lee, S. T. Lin and K. H. Chen, Diamond Relat. Mater., 13, 1553-1557 (2004). 